\title{
MPL Protein Variant
}

National Cancer Institute

\section{Source}

National Cancer Institute. MPL Protein Variant. NCI Thesaurus. Code C126823.

A variation in the amino acid sequence for the thrombopoietin receptor protein. 